\title{
Contraceptive and sexual health care issues in women with schizophrenia
}

\section{Rowan Oliver}

Fourth Year Medical Student, University of Manchester, Manchester,UK

\section{Correspondence to}

Ms Rowan Oliver, University of Manchester, Medical School,

Stopford Building, Oxford Road, Manchester M13 9PT, UK; rowan.oliver@student. manchester.ac.uk

Received 11 June 2013 Revised 24 July 2013 Accepted 30 July 2013
To cite: Oliver R. J Fam Plann Reprod Health Care 2013:39:289-291.

\section{INTRODUCTION}

Schizophrenia is a debilitating mental health disease that currently affects about $1 \%$ of the world's population with over 250000 diagnosed cases in Great Britain. The typical age of onset of the disease in females is $25-30$ years old, ${ }^{1}$ meaning that many women with this disease are of childbearing years. However, women with schizophrenia are often assumed to be subfertile, with their fertility rate estimated at $30-80 \%$ of that of the general population. ${ }^{2}$ The primary characteristics of the disease such as impairment of abstract thinking, lack of focus, impaired coping strategies, and abnormalities in perception of reality sometimes resulting in social withdrawal and reduced functional capacity - can cause behaviours that complicate family planning and deem resultant pregnancies as 'high-risk'.

\section{HISTORICAL CONTEXT}

During the last few decades, changes in societal context, health care delivery, and pharmacotherapy have effected profound changes in the sexual and reproductive lives of women with schizophrenia. It was long believed that women suffering with a chronic mental health disorder, such as schizophrenia, engaged in sexual activities less than the general population. The reasoning was thought to be due to biological aspects of the disorder itself, neuroleptic medication and also living in separate gender wards in hospitals. With the introduction of community care, atypical antipsychotics and changing attitudes within society more light is being shed on the sexual landscapes of these patients, calling for a better understanding in the management of family planning and sexual health care in this context. There is increased concern related to sexually transmitted infections (STIs) (mainly HIV) triggered by the discovery of high-risk sexual behaviours of women with schizophrenia.
In the 1950 s, the sexuality of women with schizophrenia was restricted; this was mainly due to the lack of access to marriage and chronic institutionalisation. ${ }^{3}$ Sexual activity was discouraged in the psychiatric institutions, fuelled by the stigmatisation of extramarital sex and illegitimate births. By the 1990s, after the introduction of the oral contraceptive pill, deinstitutionalisation of patients with chronic mental illness was widespread and the number of beds in psychiatric wards had fallen by $80 \%$ compared to $1955 .^{4}$ The relative fertility of women with major mental illness has increased markedly in parallel with this statistic.

Data emerging from systematically examining the sexual attitudes and practices of women with schizophrenia suggest that schizophrenia does not hinder sexual desire or activity (although psychotropic medications and hospitalisation may limit both). ${ }^{3}$ The sex lives of patients living with a long-term partner did not differ from control groups. ${ }^{3}$ However, resulting from a reduced ability to form relationships, the sex lives of most of the women were chaotic and unsatisfying, usually involving multiple partners and more risky sexual behaviours. $^{3}$ Poor judgement, impulsiveness and high rates of drug and alcohol addiction contributed to the increasing rates of unplanned and unwanted pregnancies. ${ }^{3}$ Another trend was the lack of sexual knowledge among these women. ${ }^{3}$ This included knowledge about sexual anatomy and physiology, as well as safe sex practices. ${ }^{3}$ Although attempts to teach sexual knowledge and safe sex were successful in the short term, the taught knowledge and skills started to decay if they were not regularly reinforced. ${ }^{3}$

\section{CONTRACEPTION FOR WOMEN WITH SCHIZOPHRENIA}

Regarding family planning counselling, we know that provision of these services 
is relatively rare in mental health settings. While mental health professionals agreed that family planning should be provided, a survey illustrated that only $25 \%$ of professionals raised the topic with their patients; $10 \%$ of patients confirmed this. ${ }^{5}$ It is important to understand the women's attitudes and practices related to family planning, as without this their suggested sexual landscape is more dangerous and less satisfying than for those without mental illness. ${ }^{6}$

The use of birth control in women with chronic mental illness is less than that of the general population, despite the majority of women not wanting to get pregnant. ${ }^{3}$ Grounds for this may reside in the difficulty of choosing an appropriate contraceptive method. The use of implants and intrauterine devices may become the focus of delusions of control. ${ }^{7}$ There is also the increased risk of the development of pelvic inflammatory disease due to questionable pain perception in women labelled as having schizophrenia. ${ }^{8}$ Oral contraceptive pills have been known for their mood-altering effects; ${ }^{9}$ an effect not desired in women already experiencing mood disturbances. What is more, there are issues with remembering to take pills on a daily basis.

It is recognised that there is infrequent use of barrier protection methods such as condoms in these populations, putting these women at risk of HIV infection as well as unwanted pregnancy. ${ }^{3}$ Multiple partners, risky sexual behaviours and pressurised sex deem barrier methods less effective than the other forms of contraception previously discussed. Nevertheless, barrier protection methods should always be advised to reduce the transmission of STIs such as HIV and chlamydia.

It has been suggested that the optimal birth control method for women with schizophrenia is long-acting injectable hormonal contraception. ${ }^{3}$ The most commonly used preparation provides 3 months of continuous protection and has no clinically significant interactions with antipsychotic medications. If women want both antipsychotic medications and contraception, but find it difficult to remember to take daily medications, then injectable contraception given in conjunction with depot antipsychotic medication may be helpful.

\section{CONSENT}

Use of a 'Ulysses contract' may be considered with regard to contraceptive care and informed consent. There are issues with how schizophrenia affects informed consent, so this method may be helpful in an environment where clinicians may be less attuned to this matter. The woman gives consent to initiate and continue contraception when she is most stable, with the indication that she wants her consent to remain valid if she later becomes more psychotic. This is a type of 'psychiatric advance directive', that is effectively a written document that describes what a person wants to happen with regard to their care if at some point in the future they are judged (by an appointed person) to be unable to make a decision or communicate coherently.

\section{STIS IN WOMEN WITH SCHIZOPHRENIA}

Unfortunately, the perceived sexual landscape for women with schizophrenia shows an increased risk of STIs. ${ }^{6}$ With the relatively rare provision of family planning and sexual health care within mental health settings, women are less likely to receive adequate contraception advice resulting in poor understanding of the importance of barrier protection methods in preventing the transmission of STIs. ${ }^{3}$

STIs such as HIV and AIDS are constantly in the public eye regarding sexual health issues. Since the beginning of the pandemic at least 21.8 million people have died from AIDS and more than 36 million people are living with HIV infection/AIDS. ${ }^{10}$ There have been attempts to educate populations worldwide about the risks for transmission and methods of prevention, as well as informing them of the devastating effects the virus has on the human body. However, it seems that scant attention has been paid to fully educate and watch over people with schizophrenia regarding these sexual health issues.

In 2000, the prevalence of HIV infection in Western Europe for women aged 15-49 years was $0.35 \% .^{10}$ Previous studies in this area brought to light the elevated seroprevalence of HIV infection within the population of young women suffering from schizophrenia at $5 \% .{ }^{11}$ Figures suggest that about $2 \%$ (i.e. 4000-5000) of people with schizophrenia in the UK are currently living with HIV/AIDS. ${ }^{12}$

Women with schizophrenia seem to engage in more high-risk sexual behaviours than those without a mental health disorder. In a study by Cournos et al. ${ }^{13}$ condom use was found to be infrequent at only $8 \%$. Drug and alcohol use during sex was found to be common, as was sexual exchange (for money, drugs or other goods), with many women (12\%) having sexual intercourse with a known injecting drug user. ${ }^{13}$ The chaotic sex lives of these women, sometimes involving multiple partners, coupled with scarce use of barrier contraception, are alarming in a sexual health context. As women with schizophrenia are more likely to engage in these increased sexual risk activities, this may begin to explain the high rate of seroprevalence in this population, as well as demonstrating the increased need for sexual health screening and education for these women. Although this essay focuses on women with schizophrenia, men with schizophrenia are also at increased risk of STIs and require similar sexual health care.

Much could be done in terms of clinical practice, especially developing testing and implementing methods of improving early detection of HIV-positive status and simple risk-reduction strategies. It has been suggested that all patients with a chronic mental 
health disorder be screened regarding risk-taking behaviours and those at high-risk of HIV infection be referred to a sexual health professional. ${ }^{14}$

\section{CONCLUSIONS}

The sexual and reproductive lives of women with schizophrenia have been increasingly under scrutiny since the 1990s. Profound changes in the lives of women with a chronic mental health disorder have revealed observations of concerning health care issues spanning the mental and sexual health sectors. Infrequent use of contraceptive methods, chaotic high-risk sexual behaviours, and an increased risk of HIV infection call for an alliance between mental health and sexual health professionals. With an increased awareness of these issues, the health sector can strive to implement services designed to provide women with chronic mental health disorders with the combined care needed to tackle this matter.

Competing interests None.

Provenance and peer review Not commissioned; externally peer reviewed.

\section{REFERENCES}

1 Medscape: Medscape Access. 2013. http://www.medscape.com/ viewarticle/473295 [accessed 23 July 2013].

2 Haverkamp F, Propping P, Hilger T. Is there an increase of reproductive rates in schizophrenics? Parts 1 and 2. Arch Psychiatr Nervenkr 1982;232:439-450. Arch Psychiatr Nervenkr 1982;233:167-175.

3 Miller LJ. Sexuality, reproduction, and family planning in women with schizophrenia. Schizophr Bull 1997;23:623-635.
4 Appleby L, Desai RN, Luchins DJ, et al. Length of stay and recidivism in schizophrenia: a study of public psychiatric hospital patients. Am J Psychiatry 1993;150:72-76.

5 Coverdale JH, Aruffo JA, Grunebaum H. Developing family planning services for female chronic mentally ill outpatients. Hosp Community Psychiatry 1992;43:475-478.

6 Solari H, Dickson KE, Miller L. Understanding and treating women with schizophrenia during pregnancy and postpartum. Can J Clin Pharmacol 2009;16:22-32.

7 Coverdale JH, Bayer TL, McCullough LB, et al. Respecting the autonomy of chronic mentally ill women in decisions about contraception. Hosp Community Psychiatry 1993; 44:671-674.

8 Bachrach LL. Chronic mentally ill women: emergence and legitimation of program issues. Hosp Community Psychiatry 1985;36:1063-1069.

9 Glick ID, Bennett SE. Psychiatric complications of progesterone and oral contraceptives. J Clin Psychopharmacol 1981;1:350-367.

10 World Health Organization (WHO). Epidemiological Fact Sheet on HIV/AIDS and Sexually Transmitted Infections. Geneva, Switzerland: WHO, 2000.

11 Ayuso-Mateos JL, Montanes-Lastra I, De La Garza PJ, et al. HIV infections in psychiatric patients: an unlinked anonymous study. Br J Psychiatry 1997;170:181-185.

12 Gray R, Brewin E, Noak J, et al. A review of the literature on HIV infection and schizophrenia: implications for research, policy and clinical practice. J Psychiatr Ment Health Nurs 2002;9:405-409.

13 Cournos F, Guido JR, Coomaraswamy S, et al. Sexual activity and risk of HIV infection among patients with schizophrenia. Am J Psychiatry 1994;151:228-232.

14 Gottesman II, Groome CS. HIV/AIDS risks as a consequence of schizophrenia. Schizophr Bull 1997;23:675-684.

\section{FACULTY OF SEXUAL \& REPRODUCTIVE HEALTHCARE MEMBERSHIP EXAMINATION}

The Membership Examination (MFSRH) consists of:

\section{Part 1 Multiple Choice Question paper (MCO)}

The London-based examination is held annually in April and October. Applications for the Friday $\mathbf{2 5}$ April $\mathbf{2 0 1 4}$ examination must be received by $\mathbf{3}$ January 2014 and for the Friday 17 October 2014 examination by $\mathbf{1}$ July 2014. The syllabus for the Part 1 is on the Faculty website.

\section{$\square$ Evidence Based Commentary (EBC)}

Candidates can view the released topic and candidate guidance notes for EBC on the Faculty website. There is an absolute deadline of 31 August 2014 to submit the EBC on this topic.

\section{$\square$ Part 2 Examination}

Applications for the MFSRH Part 2 to be held in Liverpool on Wednesday 11 June 2014 must be received by 3 January 2014.

Further information and the Part 2 Syllabus are on the Faculty website. The qualification is subject to re-certification every 5 years. For the current MFSRH Examination Regulations, information on all components of the MFSRH examination and application forms, please visit the Faculty of Sexual and Reproductive Healthcare website: www.fsrh.org (Examinations) or e-mail Denise Pickford: denise@fsrh.org. 